\title{
Hambatan yang Dihadapi ASEAN Defense Industry Collaboration (ADIC) dalam Menentukan Platform Persenjataannya
}

\author{
Novri Surya Ningsih \\ Universitas Indonesia
}

\begin{abstract}
ABSTRAK
Tulisan ini membahas mengenai hambatan-hambatan yang dihadapi oleh ASEAN Defense Industry Collaboration (ADIC) dalam menentukan platform persenjataannya. Dalam menganalisis hambatan tersebut, penulis merujuk pada konsep Revolusi Krida Yudha atau Revolution in Military Affairs (RMA) yang menjelaskan bahwa teknologi, doktrin, dan organisasi militer dipengaruhi oleh masing-masing anggota dari ADIC. RMA merupakan konsep yang berguna untuk menggambarkan karakteristik militer masing-masing anggota. Kausalitas yang terkonstruksi dalam penelitian ini adalah antara fitur-fitur doktriner, teknologi, dan organisasional dari penentuan platform militer dan persenjataan dalam ADIC. Hasil analisis menunjukkan bahwa terdapat perbedaan signifikan antaranggota ADIC dalam aspek teknologi, doktriner, dan organisasi militer. Perbedaan tersebut menimbulkan hambatan dalam menentukan platform persenjataan. Dengan demikian, tanpa membentuk kolaborasi yang lebih kuat dan menetapkan tujuan-tujuan kebijakan nyata untuk mengatasi ketiadaan kesamaan, ADIC tidak akan berjalan dengan efektif.
\end{abstract}

Kata Kunci: ASEAN Defense Industry Collaboration (ADIC), Platform, Persenjataan, Kerja Sama Pertahanan ASEAN, Industri Pertahanan ASEAN.

This article is a study of the impediments to the ASEAN Defense Industry Collaboration (ADIC) in determining its weapons platforms. In analyzing the impediments, this article refers to the concept of Revolution in Military Affairs (RMA) which formulates that the technology, doctrine, and military organization are influenced by each member of the ADIC. The RMA is a useful concept for portraying the military characteristics of each member. The causality constructed in this research is between the doctrinaire, technological, and organizational features in the determination of military and weapons platform in the ADIC. This article finds that there is discrepancy in existing technologies, doctrines, and military organizations among members of ADIC and it creates a strong impediment in determining weapons platforms. Without initiating stronger collaboration and setting tangible policy aims to solve common ground absence, ADIC will not go effectively.

Keywords: ASEAN Defense Industry Collaboration (ADIC), Platform, Weaponry, ASEAN Defense Collaboration, ASEAN Defense Industry. 


\section{ASEAN Defense Industry Collaboration (ADIC)}

Pada tahun 2011, ASEAN memasuki tahapan baru dalam kerja sama pertahanan dan keamanan regional dengan disetujuinya dokumen konsep pembentukan kolaborasi industri pertahanan ASEAN atau ASEAN Defense Industry Collaboration, yang selanjutnya akan dirujuk sebagai ADIC. Dokumen tersebut disetujui oleh empat negara ASEAN: Malaysia, Indonesia, Singapura dan Thailand. ADIC merupakan inisiatif pemerintah Malaysia pada ASEAN Defense Ministerial Meeting-atau ADMM-ke-5. Tujuan pembentukan kolaborasi tersebut adalah untuk mengurangi tingkat impor kebutuhan alat pertahanan negara-negara anggota ASEAN dari US \$25 milyar menjadi US \$12,5 milyar (Raghavan dan Ben-Ari 2011). Besarnya tingkat impor ASEAN tersebut dipengaruhi oleh kapabilitas negara-negara ASEAN dalam memproduksi alat pertahanan yang tidak seimbang dengan besarnya kebutuhan alat pertahanan negara-negara ASEAN. Dengan demikian, fokus utama ADIC adalah meningkatkan kapasitas ASEAN pada bidang teknologi dan industri persenjataan (ASEAN Defense Ministers Meeting 2016).

Dalam dokumen konsep ADIC telah dijabarkan kegiatan-kegiatan yang dapat dilakukan sebagai kerangka kerja ADIC. Kegiatankegiatan tersebut terangkum dalam empat kelompok: (1) pendidikan dan pelatihan di sektor industri pertahanan; (2) partnership, jointventures, dan co-production program-program industri pertahanan; (3) penelitian dan pengembangan bersama program-program industri pertahanan atau co-development; dan (4) promosi bersama dalam pengembangan program industri pertahanan (ASEAN Defense Ministers Meeting 2016). Kerangka kerja ADIC tersebut adalah cakupan ASEAN dalam melakukan kolaborasi industri pertahanan.

Lebih lanjut lagi, kerangka kerja ADIC tersebut sesuai dengan tiga bentuk kolaborasi yang dikenal dalam industri pertahanan. Bentuk yang pertama adalah reciprocal trade, di mana negara-negara yang berkolaborasi sepakat untuk saling membeli alat pertahanan yang diproduksi oleh salah satu anggota kolaborasi. Bentuk yang kedua adalah co-production, di mana perusahaan pertahanan dari satu negara memproduksi alat pertahanan yang telah dikembangkan oleh negara anggota kolaborasi lainnya. Adapun bentuk yang ketiga adalah co-development, yaitu di mana negara-negara yang berkolaborasi secara bersama-sama mengembangkan dan memproduksi alat pertahanan (Heuninckx 2008, 4). 
Jika mengacu kepada kondisi mayoritas negara-negara ASEAN, maka bentuk kolaborasi yang tepat untuk diterapkan adalah codevelopment. Co-development dianggap menjadi skema yang tepat bagi ADIC karena mencakup seluruh rangkaian proses produksi yang memberikan nilai tambah bagi setiap pihak yang berpartisipasi. Selain itu, skema ini akan mengurangi beban biaya penelitian yang ditanggung masing-masing negara, apabila dibandingkan dengan pengembangan alat pertahanan oleh masing-masing negara secara individu. Negara-negara anggota ASEAN menginginkan adanya timbal-balik dalam kolaborasi ini, meskipun terdapat ketidakseimbangan kemampuan industri pertahanan dari masingmasing negara. Asumsi yang memandang skema co-development sebagai skema yang tepat untuk diterapkan dalam ADIC didukung oleh Menteri Pertahanan Malaysia sebagai negara inisiator pembentukan ADIC. Menteri Pertahanan Malaysia menyebutkan bahwa ADIC dalam bentuk co-development akan memberikan berbagai keuntungan bagi negara-negara ASEAN. Keuntungan yang pertama berada pada skala ekonomi, yaitu semakin murahnya biaya produksi alat pertahanan per unit. Keuntungan yang kedua adalah percepatan konvergensi tingkat penguasaan teknologi industri pertahanan negara-negara ASEAN-atau sharing of technologysebagai hasil dari kolaborasi. Adapun keuntungan yang ketiga adalah spesialisasi masing-masing negara ASEAN pada area yang berbeda. Spesialisasi ini dapat didasarkan pada tingkat penguasaan teknologi masing-masing negara (Hamidi 2010, 121).

Namun, sebelum melangkah ke dalam skema co-development, permasalahan penting yang perlu dipecahkan adalah mengenai alat pertahanan apa yang kira-kira dapat dijadikan objek dalam skema codevelopment. Penyebab dari permasalahan ini adalah adanya fakta bahwa ADIC sama sekali belum menentukan jenis senjata atau alat pertahanan yang akan dikembangkan. Padahal, penentuan jenis alat pertahanan atau platform persenjataan yang akan dikembangkan merupakan hal yang paling mendasar dalam kolaborasi tersebut. Hal ini menunjukkan bahwa perkembangan ADIC sangat lamban atau tidak efektif dalam mengupayakan pelaksanaan kegiatan-kegiatan yang tertulis dalam dokumen konsep ADIC.

Perkembangan ADIC yang lamban tersebut juga terlihat dalam pertemuan ASEAN Defense Senior Officials' Meetingatau ADSOM-pada tahun 2015 di Malaysia. Pada pertemuan tersebut terjadi pembahasan mengenai ADIC, di mana Indonesia memberikan masukan agar ADIC membuat suatu rencana kerja atau cetak biru pelaksanaan program-program ADIC di masa depan 
(Laporan Kinerja Direktorat Jenderal Kerja Sama ASEAN 2015). Masukan dari Indonesia tersebut memperlihatkan bahwa ADIC belum menentukan platform persenjataan. Oleh karena itu, dalam artikel ini penulis akan menganalisis mengapa ADIC mengalami hambatan dalam menentukan platform persenjataan yang tepat untuk dikembangkan. Penulis akan menganalisis karakteristik militer masing-masing negara ADIC untuk melihat hambatan dalam mencapai kesepakatan politik pembentukan platform persenjataan ADIC. Dalam menganalisis hal tersebut, artikel ini akan menggunakan konsep Revolution in Military Affairs.

\section{Revolution in Military Affairs (RMA)}

Andrew Marshall menyatakan bahwa konsep Revolution in Military Affairs-atau RMA-adalah perubahan yang terjadi pada teknologi persenjataan dan mempengaruhi aspek lain seperti konsep organisasi atau struktur militer, dan doktrin militer. Dengan kata lain, teknologi baru akan menyebabkan perubahan dalam cara pelaksanaan perang (Maloney dan Robertson 1999, 445). RMA memiliki asumsi dasar bahwa senjata memiliki makna yang sangat signifikan bagi kekuatan negara maupun perilaku negara. Teknologi persenjataan adalah instrumen yang membuat negara unggul bagi negara lain. Oleh karena itu, RMA suatu negara sangat berhubungan erat dengan modernisasi pada sektor teknologi dan militer yang dikaitkan dengan kepentingan nasional atau keamanan negara dan mengakibatkan perubahan pada doktrin dan organisasi. Oleh karena itu, RMA negara digambarkan dalam teknologi canggih dan sistem persenjataan atau hardware, doktrin militer atau software, dan organisasi atau struktur organisasi militer yang juga disebut sebagai wetware (Dombrowski dan Ross 2008, 18).

Artikel ini akan meminjam ketiga variabel RMA tersebut untuk memperlihatkan karakteristik militer masing-masing negara ADIC. Kaitan yang diteliti dalam artikel ini adalah bagaimana karakteristik militer mempengaruhi penentuan platform persenjataan yang akan dibangun dalam kerja sama ADIC. Alasan penulis menggunakan kata "meminjam" ketiga variabel RMA adalah karena artikel ini yang tidak bertujuan untuk melihat karakteristik militer dalam strategi perang atau dampak adaptasi teknologi terhadap doktrin dan organisasi militer, melainkan hanya untuk mengidentifikasi esensi dari karakteristik militer masing-masing negara. 
Namun demikian,, Steinberg (1998, 98-102) menekankan bahwa terdapat variabel lain yang mendasari ketiga variabel tersebut dalam menentukan platform persenjataan atau kebutuhan persenjataan, yaitu ancaman. Ancaman merupakan hal yang mendasari keputusan suatu negara dalam membentuk doktrin militer, organisasi, hingga teknologi yang ada. Oleh karena itu, kebijakan pengadaan alat pertahanan sangat terkait dengan strategi dalam menghadapi prioritas ancaman militer suatu negara. Pendekatan ini didasari oleh analisis terhadap ancaman yang ada untuk disesuaikan dengan kebutuhan yang diperlukan. Prioritas ancaman harus diidentifikasi untuk melihat urgensi yang dihadapi negara, agar dapat membentuk organisasi untuk merumuskan strategi dan taktik. Evaluasi yang dilakukan kemudian adalah fokus terhadap teknologi dan kuantitas alat pertahanan untuk mendukung organisasi militer negara (Steinberg 1998, 98-102).

Menurut Stefan Markowski \& Peter Hall (1998, 12-14), teknologi militer yang sudah dimiliki oleh suatu negara dapat digunakan untuk mengidentifikasi jenis kebutuhan alat pertahanan negara. Regorson dalam Markowski \& Hall (1998, 12-14) menyatakan bahwa tujuan penggunaan variabel teknologi sebagai penentu kebutuhan alat pertahanan adalah untuk meningkatkan kapabilitas dan kinerja melalui teknologi yang lebih canggih untuk menghadapi ancaman yang ada (Markowski dan Hall 1998, 12-14). Konsepteknologitersebut yang akan digunakan dalam menganalisis jenis kebutuhan alat pertahanan atau platform persenjataan.

Selain teknologi dan organisasi, Gerald Steinberg $(1998,99)$ mengatakan bahwa doktrin militer suatu negara merupakan variabel yang sangat penting dalam menentukan jenis kebutuhan alat pertahanan. Steinberg (1998, 99) mengatakan bahwa pengadaan sistem alat pertahanan harus sesuai dengan doktrin militer atau kebijakan pertahanan suatu negara. Pembentuk doktrin militer, seperti kondisi geografis negara, merupakan hal yang sangat signifikan untuk menjadi acuan dalam pemilihan jenis kebutuhan alat pertahanan (Steinberg 1998, 99). Selain kondisi geografis, hal lain yang fundamental dalam menentukan doktrin militer adalah pengalaman militer (Pinatih 2010). Doktrin militer berfungsi sebagai pedoman pelaksanaan pertahanan negara. Hal ini dilakukan untuk menyiapkan daya tangkal dalam mencegah dan meniadakan setiap ancaman yang berasal dari luar maupun dalam negeri (Drew dan Snow 2017). Doktrin militer, dengan demikian, merupakan variabel penting dalam mengidentifikasi jenis kebutuhan senjata. 


\section{Prioritas Ancaman, Doktrin, Teknologi, dan Organisasi Militer Indonesia}

Secara geografis, Indonesia merupakan negara kepulauan terbesar di dunia. Indonesia memiliki lebih dari 17.504 pulau yang terdiri atas 13.466 pulau telah diberi nama (Forum Rektor Indonesia 2015). Selain itu, Indonesia memiliki luas wilayah yurisdiksi nasional sekitar 7,8 juta km persegi, yang dua pertiganya merupakan wilayah laut dengan luas sekitar 5,9 juta kilometer persegi. Wilayah tersebut mencakup Zona Ekonomi Eksklusif Indonesia-atau ZEEI-dengan luas sekitar 2,7 juta kilometer persegi, Laut Wilayah, Perairan Kepulauan, dan Perairan Pedalaman dengan luas sekitar 3,2 juta kilometer persegi. Hal ini memberikan Indonesia garis pantai yang panjang, yaitu sekitar 81.000 kilometer (Marsetio 2013, 1-2). Indonesia berbatasan langsung dengan 10 negara tetangga, maka dapat dikatakan Indonesia memiliki perbatasan yang panjang untuk dijaga dan diamankan (Badan Nasional Pengelola Perbatasan Republik Indonesia 2012, 1-2). Kawasan perbatasan juga banyak diwarnai oleh berbagai aktivitas pelanggaran hukum lintas batas, seperti perdagangan ilegal, pertambangan ilegal, migrasi ilegal, perdagangan manusia, penyelundupan manusia, peredaran narkotika, dan terorisme (Badan Nasional Pengelola Perbatasan Republik Indonesia 2012, 7). Oleh karena itu, Indonesia sangat perlu melakukan tindakan pengamanan yang ketat terhadap area-area perbatasan negara.

Indonesia memiliki empat chokepoint dari sembilan chokepoint strategis dunia dan tiga Alur Laut Kepulauan Indonesia atau ALKI (Lestari 2010, 1-2). Keempat chokepoint tersebut meliputi Selat Malaka, Selat Sunda, Selat Lombok dan Selat Ombai. Kemampuan Indonesia untuk mengamankan keempat chokepoint akan berpengaruh langsung terhadap situasi keamanan dan ekonomi kawasan Asia Pasifik secara keseluruhan (Badan Nasional Pengelola Perbatasan Republik Indonesia 2011, 10). Dari keempat chokepoint tersebut, Selat Malaka merupakan selat yang memiliki fungsi paling strategis. Selat Malaka berfungsi sebagai jalur komunikasi laut atau Sea Line of Communication atau SLOC bagi perdagangan dunia. Setiap tahun, kurang lebih 60.00o kapal melintasi Selat Malaka. Aktivitas pelayaran di Selat Malaka tersebut menjadikan selat ini sebagai sasaran perompakan terhadap kapal-kapal yang melintas (Lestari 2010, 1-2).

Sebagai respons terhadap kompleksitas permasalahan batas wilayah dan keamanan laut Indonesia tersebut, Buku Putih Pertahanan 
Indonesia tahun 2008 menyatakan bahwa prioritas ancaman Indonesia berfokus pada keamanan wilayah maritim, khususnya wilayah-wilayah perbatasan. Potensi ancaman tersebut menuntut pertahanan negara yang cukup kuat dan mampu menjangkau seluruh wilayah secara maksimal (Departemen Pertahanan Republik Indonesia 2008, 53). Oleh karena itu, pada tanggal 12 Januari 2007 Mabes TNI menerbitkan Doktrin Tri Dharma Eka Karma-atau Tridek-yang menjadi doktrin militer Indonesia (Markas Besar Tentara Nasional Indonesia 2010, 18).

Terdapat beberapa hal penting yang disebutkan dalam doktrin Tridek, yaitu sistem pertahanan semesta, operasi militer untuk perang atau OMP, dan operasi militer selain perang atau OMSP. Dalam sistem pertahanan semesta, fokus pertahanan Indonesia sudah mengarah pada penguatan aspek maritim. Ciri kewilayahan merupakan gelar kekuatan pertahanan yang tersebar di seluruh wilayah NKRI, sesuai dengan kondisi geografis sebagai satu kesatuan pertahanan (Departemen Pertahanan Republik Indonesia 2008, 43). Dalam sistem OMP dan OMSP dikatakan bahwa apabila ancaman meningkat, maka penggunaan kekuatan TNI untuk me-laksanaan OMSP akan menjadi semakin besar. Sebagian besar ancaman yang dimaksud adalah ancaman maritim, seperti pelanggaran wilayah oleh negara lain (Departemen Pertahanan Republik Indonesia 2008, 50-51). Asumsi yang dapat ditarik dari penjelasan ini adalah bahwa Indonesia membutuhkan alat pertahanan atau senjatayang mendukung pertahanan maritim. Indonesia membutuhkan kapal yang memiliki teknologi untuk mendeteksi kemungkinan terjadinya pelanggaran hukum di laut serta mengidentifikasi jenis dan pelaku tindak pelanggaran hukum di laut.

Kemampuan Angkatan Laut dalam mengamankan wilayah maritim Indonesia dapat dinilai dari alat pertahanan yang mendukung Angkatan Laut dalam melaksanakan patroli keamanan laut. Oleh karena itu, Indonesia melakukan berbagai upaya untuk memperkuat kekuatan laut melalui pembentukan Sistem Armada Terpadu, yang sesuai dengan perencanaan strategis jangka mendatang dalam Kekuatan Pertahanan Minimum atau Minimum Essential Force 2024. Pembangunan MEF tersebut akan mengarah pada penguatan kapal selam, fregat, dan korvet atau kapal patroli (Perwita dan Komeini t.t.). Namun, terdapat beberapa hal yang harus diperhatikan, yaitu prioritas ancaman dan kuantitas yang seharusnya lebih menekankan pada korvet. Oleh karena itu, Indonesia menetapkan langkah untuk memodernisasi angkatan laut dengan mengem- 
bangkan Angkatan Laut hingga memiliki armada 274 kapal dan menyertakan lebih banyak kapal korvet (Indo-Asia-Pacific Defense Forum t.t.).Prioritas ancaman Indonesia, seperti pelanggaran perbatasan oleh kapal-kapal perikanan asing, migrasi ilegal, perompakan, dan ancaman-ancaman maritim lainnya menimbulkan kebutuhan Indonesia atas kapal korvet. Kapal korvet memiliki manuver tinggi yang berfungsi untuk mengejar musuh, sehingga sangat efektif untuk mengatasi pelanggaran perbatasan dan ancaman maritim lainnya (Budiarto t.t.). Hal lain yang menjadi pertimbangan adalah kuantitas kapal korvet yang dimiliki Indonesia. Indonesia hanya memiliki 72 kapal korvet yang siap untuk menjaga keamanan Indonesia (The Military Balance 2013). Oleh karena itu, perlu diperhatikan apakah kuantitas 72 kapal korvet dapat melingkupi seluruh wilayah maritim Indonesia. Dibutuhkan perhitungan matematika untuk menjawab pertanyaan tersebut. Supriadi melakukan studi mengenai perhitungan cakupan wilayah patroli Indonesia dengan menggunakan rumus lingkaran, yang digunakan berdasarkan kemampuan jangkau radar yang dimiliki oleh kapal (Hakim 2010). Karena kapal yang diidentifikasi adalah kapal korvet, maka kemampuan jangkau radar yang digunakan adalah 48 nautical mile (Hakim 2010). Maka perhitungan tersebut adalah:

Rumus Lingkaran

$$
L \text { (luas) }=3.14 \times 48 \mathrm{~nm} \times 48 \mathrm{~nm}
$$

Dengan asumsi 1 mil laut adalah 1,855 km, maka:

$$
\begin{aligned}
L \quad & =3.14 \times(48 \times 1,855) \times(48 \times 1,855) \\
& =24,894 \mathrm{~km}^{2}
\end{aligned}
$$

Maka, jangkauan radar 1 kapal korvet adalah 24,907 km². Dengan asumsi bahwa luas wilayah maritim Indonesia adalah 5.900.00o $\mathrm{km}^{2}$, maka dibutuhkan kapal korvet sebanyak:

$$
\begin{aligned}
\text { Kapal korvet yang dibutuhkan } & =5.900 .000 \mathrm{~km}^{2}: 24,894 \mathrm{~km}^{2} \\
& =237,004 \text { (dibulatkan menjadi 237) }
\end{aligned}
$$

Berdasarkan hitungan tersebut, Indonesia masih membutuhkan kapal korvet untuk menjaga keamanan maritim Indonesia sehingga platform persenjataan yang tepat untuk dibangun bagi Indonesia adalah kapal korvet. Selain itu, kebutuhan terhadap kapal korvet didukung oleh Organisasi TNI AL yang bertugas mengoperasikan 
kapal korvet, yaitu koarmada. Terdapat dua koarmada dengan 14 Lantamal yang membawahi 63 pangkalan laut Indonesia (TNI AL t.t.). Oleh karena itu, jika merujuk kepada ancaman yang ada, Indonesia sangat membutuhkan lebih banyak kapal patroli atau korvet dari jumlah saat ini yang hanya 72 kapal korvet untuk melakukan operasi laut dari 63 pangkalan laut.

\section{Prioritas Ancaman, Doktrin, Teknologi, dan Organisasi Militer Singapura}

Singapura merupakan negara yang memiliki kelemahan geografis. Hal ini disebabkan oleh luas wilayah Singapura yang sangat kecil, yakni dengan total luas wilayah sekitar 707,1 km persegi dan populasi sekitar lima juta penduduk (Goh 2009). Oleh karena itu, Singapura harus membentuk doktrin militer yang mampu melakukan tindakan penggentaran terhadap ancaman militer konvensional (The Ministry of Defence t.t.). Selain kondisi geografis, sejarah juga merupakan faktor yang mempengaruhi Singapura dalam melihat prioritas ancaman (Lam t.t.). Letak geografis Singapura berada di antara Malaysia dan Indonesia-dua negara yang memiliki sejarah sengketa dengan Singapura. Faktor sejarah tersebut semakin memicu Singapura untuk membentuk doktrin militer yang mampu melakukan tindakan penggentaran atau deterrence terhadap ancaman militer konvensional.

Dalam menghadapi prioritas ancamannya, yakni ancaman militer konvensional, maka Singapura membentuk doktrin pertahanan semesta atau total defense yang menggabungkan kekuatan Singapore Armed Forces atau SAF dan masyarakat sipil. Doktrin pertahanan semesta pertama kali diperkenalkan pada tahun 1984 untuk menyoroti kepentingan pertahanan Singapura. Dalam doktrin pertahanan semesta, setiap individu diorganisasikan untuk melakukan pertahanan terhadap segala bentuk ancaman, baik militer maupun non-militer (The Ministry of Defence t.t.).

Strategi militer yang dibentuk Singapura adalah Integrated Knowledge based Command and Control atau IKC2 untuk mendukung SAF (Lam t.t.). Strategi tersebut bertujuan untuk meningkatkan kemampuan penggentaran Singapura terhadap serangan agresi militer konvensional. Strategi IKC2 mengintegrasikan berbagai sensor dan penembak, sehingga tentara Singapura memiliki kemampuan untuk mengawasi medan tempur dan memiliki jaringan 
komunikasi yang canggih (Lam t.t.). Strategi ini sangat membutuhkan teknologi yang menekankan pada akuisisi, pengembangan, integrasi teknologi dalam komando, pengendalian dengan sistem Intelligence, Surveilance, dan Reconaisance atau ISR, serta presisi terpadu. Oleh karena itu, berdasarkan doktrin pertahanan semesta yang menciptakan strategi IKC2, Kementerian Pertahanan Singapura menyatakan bahwa alat pertahanan yang memiliki kemampuan penggentaran dengan teknologi informasi canggih adalah hal yang paling dibutuhkan oleh Singapura (Luthfi 2012).Oleh karena itu, pembangunan mengarah pada penguatan kemampuan penggentaran dan jaringan komunikasi yang canggih. Berdasarkan hal tersebut, maka asumsi platform yang tepat adalah teknologi pesawat tempur. Sebagai negara yang memprioritaskan kemampuan penggentaran, maka pasukan militer Singapura harus mampu mengontrol cara kerja senjata yang memiliki kemampuan penggentaran. Jika melihat organisasi angkatan udara Singapura yang ada, maka organisasi yang bertugas mengoperasikan senjata penggentaran adalah Air Combat Command atau ACC (Singapore Government 2008). Berdasarkan kapabilitas Singapura, organisasi ACC telah dilengkapi dengan persenjataan yang memiliki kemampuan penggentaran.

\section{Prioritas Ancaman, Doktrin, Teknologi, dan Organisasi Militer Thailand}

Berbeda dengan cara Indonesia dan Singapura dalam melihat prioritas ancaman yang dipengaruhi oleh kondisi geografis, Thailand melihat prioritas ancaman berdasarkan kondisi domestik. Ancaman keamanan terbesar bagi Thailand adalah ancaman internal, yaitu konflik Thailand Selatan (Pongsudhirak t.t.). Konflik tersebut berasal dari pemberontakan kelompok separatis Thailand Selatan yang sudah terjadi sejak tahun 1909. Konflik ini terkait dengan hak otonomi khusus dan kemerdekaan yang dituntut oleh Thailand Selatan dan hingga saat ini belum menghasilkan kesepakatan (Engval dan Andersson 2014).Secara historis, konflik tersebut dimulai dengan aneksasi yang menyebabkan jatuhnya kerajaan Thailand Selatan ke tangan kerajaan Thailand dan munculnya perjanjian Anglo-Siam. Perjanjian tersebut menegaskan bahwa wilayah Thailand Selatan merupakan bagian dari Thailand (Engval dan Andersson 2014). Hal ini mendorong pemerintah Thailand untuk menerapkan negara modern dengan ideologi Buddhisme, padahal mayoritas penduduk Thailand Selatan adalah Muslim. Kondisi ini menjadi pemicu bagi masyarakat Thailand Selatan untuk membentuk kelompok separatis 
yang melakukan pertentangan dan pemberontakan. Pemberontakanpemberontakan tersebut semakin meningkat dengan munculnya kesenjangan kondisi ekonomi, politik dan sosial budaya antara pemerintah Thailand pusat dan masyarakat Thailand Selatan (Engval dan Andersson 2014).Pada tahun 2008, tercatat korban jiwa sekitar 422 milisi sipil dan 74 personel pemerintah. Korban luka yang tercatat meliputi sekitar 613 masyarakat sipil dan 425 personel pemerintah. Selain itu juga tercatat 741 serangan pistol dan 218 pengeboman. Pada bulan Juli 2009, jumlah korban jiwa meliputi sekitar 1,788 masyarakat Melayu Muslim Thailand dan 1,384 masyarakat Buddha Thailand. Korban luka meliputi 3,222 masyarakat Buddha Thailand dan 1,633 masyarakat Muslim Thailand (Moore 2010). Hal ini menempatkan Thailand pada peringkat ke-10 tertinggi di dunia sebagai negara dengan ancaman kejahatan terorisme atau separatisme.

Tingginya jumlah serangan separatisme di Thailand yang disertai jatuhnya korban jiwa dalam jumlah yang besar bukan berarti tidak ada upaya penyelesaian yang dilakukan oleh pemerintah Thailand. Pemerintah Thailand terus membuat kebijakan-kebijakan politik dan ekonomi untuk mengatasi pemberontakan yang dilakukan oleh kelompok separatis ini. Pemerintah Thailand juga mengambil kebijakan militer untuk membentuk doktrin Counter Insurgency atau COIN. Doktrin COIN merupakan perspektif pemerintah Thailand dalam memandang insurgensi yang terjadi di Thailand Selatan. Keberhasilan doktrin COIN dalam menghadapi ancaman separatisme dan terorisme tergantung pada pengaplikasian operasi berdasarkan kualitas intelijen dan senjata yang digunakan. Oleh karena itu, kebutuhan militer dan alat pertahanan semakin meningkat di Thailand.

Agar penanganan terhadap kelompok separatis lebih efektif, pemerintah Thailand mengalokasikan lebih dari 49 persen anggaran pertahanan untuk kebutuhan persenjataan Angkatan Darat. Angkatan Laut hanya memperoleh 19 persen dan Angkatan Udara hanya 18 persen. Pemerintah Thailand bermaksud untuk memfokuskan anggaran pertahanan pada pengadaan senjata untuk menangani pemberontakan Thailand Selatan, seperti kendaraan tempur lapis baja, helikopter untuk Angkatan Darat, satelit, pistol, senapan laras panjang, dan amunisi (International Trade Administration 2016). Oleh karena itu, pembangunan mengarah pada penguatan Angkatan Darat Thailand. Hal ini dilakukan agar penanganan terhadap prioritas ancaman yang dihadapi Thailand-kelompok separa- 
tis Thailand Selatan-menjadi lebih efektif. Penguatan Angkatan Darat didukung oleh struktur Angkatan Darat Thailand. Struktur Angkatan Darat Thailand terdiri atas empat organisasi dalam empat area. Organisasi yang bertanggung jawab untuk melakukan operasi pengamanan terhadap Thailand Selatan adalah Fourth Army. Strategi yang digunakan Fourth Army untuk menghadapi kelompok separatis adalah perang gerilya (Global Security t.t.). Oleh karena itu, senjata yang dibutuhkan Thailand adalah senjata yang mendukung strategi gerilya, yaitu kendaraan tempur lapis baja, pistol, senapan, dan amunisi.

\section{Prioritas Ancaman, Doktrin, Teknologi, dan Organisasi Militer Malaysia}

Malaysia memiliki kesamaan cara dengan Singapura dalam melihat prioritas ancaman, yaitu berdasarkan faktor letak geografis dan sejarah nasional. Berdasarkan kedua faktor tersebut, prioritas ancaman bagi Malaysia berasal dari pihak eksternal. Ancaman Malaysia diidentifikasi berasal dari negara-negara tetangga, yaitu Indonesia, Thailand, dan Singapura. Walaupun hubungan antara Malaysia dengan negara-negara tersebut berjalan dengan baik, sengketa yang pernah terjadi antara Malaysia dengan ketiga negara tersebut mempengaruhi cara pandang Malaysia terhadap prioritas ancaman dan pembangunan strategi pertahanan (Keling et al. 2011).Meskipun Indonesia tidak pernah melakukan konfrontasi atau tindakan ancaman kepada Malaysia setelah Perang Dingin berakhir, sejarah konfrontasi pada tahun 1965 dan sengketa teritorial mengambil tempat yang penting dalam menentukan prioritas ancaman dan isu keamanan Malaysia di masa depan. Perspektif yang sama juga muncul terhadap Thailand dan Singapura (Keling et al. 2011). Malaysia pernah memiliki beberapa sengketa darat dan maritim dengan Indonesia, salah satunya adalah sengketa Selat Malaka. Sengketa tersebut terkait belum disepakatinya batas Zona Ekonomi Eksklusif di Selat Malaka oleh kedua negara. Indonesia dan Malaysia saling mengklaim garis batas Zona Ekonomi Eksklusif di Selat Malaka, sehingga terbentuk kawasan tumpang tindih atau overlapping claim maritime area (Mardiah 2014). Malaysia juga pernah memiliki sengketa wilayah dengan Thailand, yaitu wilayah Bukit Jeli. Bukit Jeli adalah wilayah dengan luas sekitar 45 hektar yang dipersengketakan saat Malaysia melakukan demarkasi (Armandhanu 2015). Selain itu Malaysia juga memiliki sengketa wilayah dengan Singapura, seperti sengketa wilayah Pedra Branca. 
Hingga tahun 2008, Mahkamah Internasional atau International Court of Justice memberikan hak kedaulatan Pedra Branca kepada Singapura (Armandhanu 2015).

Dalam menghadapi berbagai ancaman yang ada, Malaysia menerapkan doktrin pertahanan menyeluruh atau Hanruh. Dalam aspek militer, tujuan Malaysia dalam membentuk doktrin tersebut adalah untuk menunjukan transisi perhatian pemerintah Malaysia terhadap modernisasi persenjataan dan peningkatan kemampuan militer Malaysia. Perhatian lebih terhadap pembangunan kapabilitas militer tersebut dipengaruhi oleh potensi ancaman eksternal yang ada. Proses penguatan pertahanan dan sistem militer dilakukan agar Malaysia mampu menghadapi ancaman dan tantangan, khususnya yang berasal dari lawan dengan teknologi canggih. Malaysia juga melakukan perubahan terhadap pasukan militernya dengan menerapkan Network Centric Warfare atau NCW. Hal tersebut bertujuan untuk meningkatkan kemampuan pasukan militer Malaysia untuk mengimbangi pasukan militer negara-negara tetangga (Keling et al. 2011).Dari penjelasan di atas, terlihat bahwa pembentukan doktrin Hanruh dipengaruhi oleh prioritas ancaman eksternal Malaysia. Dengan membentuk doktrin Hanruh, pertahanan Malaysia diharapkan dapat menangkal berbagai ancaman eksternal. Oleh karena itu, Malaysia berusaha mengadakan alat-alat pertahanan yang canggih. Hal ini dilakukan Malaysia untuk membangun strategi penggentaran (Abul'as 1998). Malaysia membutuhkan alat pertahanan yang memiliki daya tangkal dan kemampuan penggentaran yang kuat untuk menghadapi ancaman eksternal, maka asumsi platform yang tepat adalah teknologi pesawat tempur.

Pada umumnya, pesawat tempur yang dimiliki Malaysia adalah pesawat tempur generasi keempat seperti MiG-29 Fulcrum dan F/A-18 Hornet yang tentu belum memiliki kemampuan yang sebanding dengan pesawat tempur generasi 4,5 dan generasi kelima (The Military Balance 2013). Pesawat tempur generasi kelima memiliki kecepatan terbang suprasonik dan tidak terdeteksi oleh radar, sehingga memiliki kemampuan yang tinggi untuk menyerang dan menetralisir musuh. Selain itu, pesawat generasi kelima memberikan kemampuan kepada pilot untuk meningkatkan kepekaan terhadap situasi, atau situational awareness, dan superioritas di atas lawan. Hal ini memberikan kekuasaan dan kesempatan ketahanan yang lebih besar pada pertarungan udara. Oleh karena itu, Malaysia membutuhkan jenis pesawat tempur generasi terbaru apabila negara tersebut berkomitmen untuk mempersenjatai divisi 
pertama angkatan udaranya sebagai organisasi yang mengoperasikan senjata penggentaran untuk menyeimbangkan kemampuan dengan senjata penggentar milik negara tetangga Malaysia.

\section{Kesimpulan}

Berdasarkan penjelasan yang ditunjukan di atas, maka sulit bagi ADIC untuk menentukan jenis platform persenjataan yang akan dikembangkan. Hal tersebut dikarenakan kebutuhan senjata setiap negara anggota ADIC berbeda, sehingga keinginan ADIC untuk mengembangkan atau memproduksi alat pertahanan bersama terbilang sulit. Meskipun semangat deklarasi pembentukan ADIC tersebut didukung oleh para pemimpin ASEAN, perbedaan kebutuhan cukup mempersulit ADIC untuk berjalan secara efektif karena bentuk kolaborasi yang tepat untuk diterapkan di ASEAN dapat dikatakan adalah co-development. Sebagai konsekuensi dari hal tersebut, platform persenjataan yang akan dikembangkan harus memiliki kesamaan pada masing-masing negara anggota ADIC sebagai hal yang mendasari kerja sama tersebut.

Penjelasan di atas memperlihatkan bahwa masing-masing negara anggota ADIC memiliki perbedaan ancaman, sehingga memiliki perbedaan pada doktrin yang dikembangkan, teknologi yang dibutuhkan, dan organisasi yang dibentuk. Hal ini menyulitkan ADIC dalam merumuskan platform persenjataan yang seragam sebagai esensi dari pembentukan kerjasama. Dapat dikatakan bahwa tidak terdapat kesamaan atau common ground antaranggota ADIC dalam menentukan jenis platform persenjataan. Oleh karena itu, jika merujuk kepada doktrin, teknologi, dan organisasi yang ada, kerja sama ADIC diasumsikan tidak akan berjalan secara efektif. Dengan demikian dibutuhkan satu kebijakan dari keempat negara ADIC yang bertujuan untuk menjembatani berbagai perbedaan yang ada. Hal tersebut membawa analisis ini pada kesimpulan bahwa sangat dibutuhkan keputusan bersama antarnegara anggota ADIC. 


\section{Daftar Pustaka}

\section{Buku}

Moore, Jeff M., 2010. The Thai Way of Counterinsurgency. Exeter: The University of Exeter: 1-465.

Steinberg, Gerald, 1998. Arms Procurement Decision Making Volume I: China, India, Israel, Japan, South Korea andThailand. Oxford: Oxford University Press: 1-304.

The Military Balance, 2013. Asia. London: Routledege: 245-352.

\section{Jurnal Ilmiah}

Dombrowski, Peter, dan Andrew L. Ross, 2008. "The Revolution in Military Affairs, Transformation and the Defence Industry". Security Challenges, 4(4): 13-38.

Engvall, Anders \& Magnus Andersson, 2014. "The Dynamics of Conflict in Southern Thailand". Stockholm School of Economics Asia Working Paper, 33: 169-89.

Goh, Yihan, 2009. "Tort Law in the Face of Land Scarcity in Singapore". Arizona Journal of International \& Comparative Law, 26(2): 335-91.

Hamidi, Ahmad Zahid, 2010. "ASEAN Defence Industry Collaboration; Potential, Challenges and Way Forward", The Journal of Defense and Security, 1(2): 119-28.

Heuninckx, B., 2008. "APrimerto Collaborative DefenceProcurement in Europe: Troubles, Achievements and Prospects", Public Procurement Law Review, 17(3): 123-45.

Keling, Mohamad Faisol, Mohd Na'eim Ajis, Md. Shukri Shuib, Muhammad Fuad Othman, dan Hishamudin Md.Som., 2011. "The Malaysian Government's Efforts in Managing Military and Defence Development", International Journal of Business and Social Science, 2(12): 180-93.

Maloney, Sean M, dan Scot Robertson, 1999. "The Revolution in Military Affairs: Possible Implications for Canada", International Journal, 54(3): 443-62. 
Markowski, Stefan, dan Peter Hall, 1998. "Challenges of Defence Procurement”, Defence and Peace Economics 9(1-2): 12-14.

Marsetio, 2013. "Strategi TNI Angkatan Laut Dalam Pengamanan Batas Maritim NKRI: Kajian Historis-Strategis", Jurnal Sejarah CITRA LEKHA. 17(1): 1-18.

\section{Publikasi Pemerintah}

Badan Nasional Pengelola Perbatasan Republik Indonesia, 2011. Peraturan Badan Nasional Pengelola Perbatasan Republik Indonesia Nomor 1 Tahun 2011 Tentang Desain Besar Pengelolaan Batas Wilayah Negara dan Kawasan Perbatasan Tahun 2011-2025. Jakarta: Badan Nasional Pengelola Perbatasan Republik Indonesia.

Badan Nasional Pengelola Perbatasan Republik Indonesia, 2012. Peraturan Badan Nasional Pengelola Perbatasan Nomor 3 Tentang Rencana Strategis Badan Nasional Pengelola Perbatasan Tahun 2011-2014. Jakarta: Badan Nasional Pengelola Perbatasan Republik Indonesia: 1-439.

Departemen Pertahanan Republik Indonesia, 2008. Buku Putih Pertahanan Indonesia 2008. Jakarta: Departemen Pertahanan Republik Indonesia.

International Trade Administration, 2016. "Thailand - Defense and Security", International Trade Administration [online]. dalam https://www.export.gov/article?id=Thailand-defenseand-security [diakses 12 April 2017].

Markas Besar Tentara Nasional Indonesia, 2010. Lampiran Peraturan Panglima TNI. Jakarta: MABES TNI: 5-88. Indo-AsiaPacific Defense Forum, t.t., "Kekuatan Geopolitik Mendorong Modernisasi Militer di Seluruh Indo-Asia-Pasifik". Indo-AsiaPasific Defense Forum [online]. dalam http://apdf-magazine. com/id/modernisasi-maritim/ [diakses 12 April 2017].

"Laporan Kinerja Direktorat Jenderal Kerja Sama ASEAN", 2015, Kementerian Luar Negeri Republik Indonesia [online]. dalam http://www.kemlu.go.id/AKIP/LKJ\%20Ditjen\%20KSA.pdf [diakses 23 Oktober 2016]. 
Tentara Nasional Indonesia Angkatan Laut. "Struktur Organisasi TNI AL", TNI $A L$ [online]. dalam http://www.tnial.mil.id/ Aboutus/StrukturOrganisasi.aspx [diakses 20 April 2017].

The Ministry of Defence, t.t. "Defence Challenges in the 21st Century". Singapore Ministry of Defence [online]. dalam https://www.mindef.gov.sg/dam/publications/eBooks/ More_eBooks/ds21.pdf [diakses 12 April 2017].

\section{Laporan Penelitian}

Abul'as, MN., 1998. “The Malaysian Army”, Student Repository [online]. dalam http://studentsrepo.um.edu.my/2300/5/ BAB_2.pdf [diakses 13 April 2017].

Budiarto, Galih, t.t. "Pengujian Posisi Step Hull Pada Kapal Perang Korvet Nasional Ukuran 90 Meter Dengan Pendekatan Analisis CFD”, Digilib ITS [online]. dalam http://digilib.its.ac.id/ public/ITS-Undergraduate-16596-Abstract_id-pdf.pdf [diakses 18 April 2017].

Hakim, M. Fathoni, 2010. "Perjanjian Keamanan Indonesia Australian Upaya Indonesia Untuk Mencegah Gerakan Separatisme di Indonesia Timur", Perpustakaan Universitas Indonesia [online]. dalam http://lib.ui.ac.id/ file?file $=$ digital/135537-T\%2027969-Perjanjian\%2okeamanan-Analisis.pdf [diakses 12 April 2017].

Irawan, Denny, 2013. Simulasi Pembagian Peran 'Ideal' Negara Anggota ASEAN Dalam Pengembangan ASEAN Defense Industry Collaboration (ADIC): Studi Kasus Armored Personnel Carrier (APC) Anoa $6 x 6$ Pindad. Skripsi. Depok: Universitas Indonesia: 1-140.

Lam, Peng Er, t.t. "Singapore's Security Outlook: The Immutability of History, Geography and Demography?”, National Institute for Defence Studies [online]. dalam http://www.nids.mod. go.jp/english/publication/joint_research/series5/pdf/5-4. pdf [diakses 10 April 2017].

Lestari, A., 2010. Strategi Pertahanan Indonesia di Selat Malaka: Tawaran Proliferation Security Initiative Periode 20062008. Tesis Magister. Depok: Universitas Indonesia: 1-126. 
Luthfi, Mokhamad, 2012. Implementasi Revolution in Military Affairs (RMA) Dalam Kebijakan Pertahanan Indonesia. Tesis. Depok: Universitas Indonesia: 1-111.

Mardiah, 2014. Kajian Terhadap Sosialisasi Nota Kesepahaman Indonesia - Malaysia Tentang Penangkapan Ikan oleh Nelayan di Wilayah Tumpang Tindih Selat Malaka, Sumatera Utara. Tesis. Bogor: Institut Pertanian Bogor: 1-44.

Perwita, AA Banyu, dan Yugolastarob Komeini, t.t. “Kesiapan Kekuatan Laut Indonesia Dalam Menghadapi Keamanan Maritim Indonesia di Asia Tenggara", TNI AL [online]. dalam http:// pusjianmar-seskoal.tnial.mil.id/Portals/o/Kesiapan\%20 Kekuatan\%2olaut\%2oIndonesia\%2odi\%2okawasan-4.pdf [diakses 13 April 2017].

Pinatih, Ni Komang Desy Setiawati Arya, 2010. "Variasi Doktrin", Perpustakaan Universitas Indonesia [online]. dalam http://lib.ui.ac.id/file?file=digital/131531-T\%2027582-\%20 Variasi\%20doktrin-Pendahuluan.pdf [diakses 10 April 2017].

Pongsudhirak, Thitinan, t.t. "Thailand's Security Outlook: External Trends and Internal Crises", dalam Asia Pacific Countries' Security Outlook and its Implications for the Defense Sector [online]. dalam http://www.nids.mod.go.jp/english/ publication/joint_research/series5/pdf/5-6.pdf [diakses 12 April 2017].

Raghavan, S. \& Guy Ben-Ari, 2011. "DLLG Current Issues No. 25: ASEAN Defense Industry Collaboration”, CSIS [online]. dalam https://www.csis.org/analysis/diig-current-issues-no-25-asean-defense-industry-collaboration [diakses 23 Oktober 2016].

\section{Artikel Online}

Armandhanu, Denny, 2015. "Sengketa Perbatasan Malaysia dengan Berbagai Negara", CNN Indonesia [online]. dalam http:// studentsrepo.um.edu.my/2300/5/BAB_2.pdf [diakses 13 April 2017].

ASEAN Defense Ministers' Meeting, t.t. ASEAN Defense Ministers' Meeting [online]. dalam https://admm.asean.org/ [diakses 23 Oktober 2016]. 
Drew, Dennis, dan Don Snow, t.t. "Military Doctrine" [online]. dalam http://webcache.googleusercontent.com/ search?q=cache:http://www.au.af.mil/au/awc/awcgate/ readings/drew1.htm [diakses 1 April 2017].Forum Rektor Indonesia, 2015. "Naskah Akademik", Universitas Negeri Yogyakarta [online]. dalam http://fri2016.uny.ac.id/sites/ fri2016.uny.ac.id/files/2.\%20NASKAH\%20AKADEMIS.pdf [diakses 10 April 2017].

Global Security, t.t. "Royal Thai Army", Global Security [online]. dalam http://www.globalsecurity.org/military/world/ thailand/army-intro.htm [diakses 20 April 2017]. 
Hambatan yang Dihadapi ASEAN Defense Industry Collaboration (ADIC)

dalam Menentukan Platform Persenjataan 